\title{
2 Boyutlu Platform Oyunların Tarihsel Gelişimi ve Günümüz Platform Oyunlarında Kullanılan Dijital İllüstrasyonların Çözümlenmesi
}

\author{
Semih Deli1 ${ }^{1 *}$ \\ 1* Başkent Üniversitesi, İletişim Fakültesi, İletişim ve Tasarımı Bölümü, Ankara, Türkiye, (ORCID: 0000-0003-0358-2344), semihdelil@gmail.com
} (İlk Geliş Tarihi 31.05.2020 ve Kabul Tarihi 30.10.2020)

(DOI: $10.31590 /$ ejosat.745977)

ATIF/REFERENCE: Delil. S (2020). 2 Boyutlu Platform Oyunların Tarihsel Gelişimi ve Günümüz Platform Oyunlarında Kullanılan Dijital İllüstrasyonların Çözümlenmesi. Avrupa Bilim ve Teknoloji Dergisi, (2020), 472-478.

Öz

Türün oynanabilirliği ve renkliliği hedef kitlesi video oyunları olan kullanıcılar tarafından çoğu zaman tercih sebebidir. Bu tercihin en önemli aktörlerinden birisi dijital illüstrasyon sanatının kullanılmış olmasıdır. İllüstrasyon sanatı türün arayüzlerinin gelişip halen popüler olmasına sebep olan etkenlerin başında gelmektedir. Bu bağlamda çalışmanın amacı uygulama mağazası üzerinden edinilen satış rakamları üzerinden seçilmiş günümüz platform oyunu örneklerini incelemektir. Çalışma için seçilen Ori, Gris, Cup Head ve Hollow Knight isimli oyunlardaki dijital illüstrasyon örneklerinin platform oyunlarını nasıl etkilediğine yönelik verileri teknik ve göstergebilim açıdan değerlendirmektir.

Anahtar Kelimeler: Dijital illüstrasyon, platform oyunları, dijital sanat.

\section{Historical Development of 2D Platform Games and Analysis of Digital Illustrations Used in Today's Platform Games}

\begin{abstract}
Platform games are one of the most preferred video game types from past to present. The playability and colorfulness of the genre is often preferred by users with video games. One of the most important actors of this choice is the use of digital illustration art. The art of illustration is one of the factors that cause the interfaces of the genre to develop and become popular. In this context, the aim of the study is to examine the examples of platform games that are selected from the sale. To evaluate the data about how the digital illustration examples in the games named Ori, Gris, Cup Head and Hollow Knight, selected for the study, affect the platform games from a technical and semiotic perspective.
\end{abstract}

Keywords: Digital illustration, platform games, 2D platform games, digital art.

\footnotetext{
*Sorumlu Yazar: semihdelill@gmail.com, semihd@baskent.edu.tr
} 


\section{Giriş}

Video oyunları çağımızın vazgeçilmez eğlence araçlarındandır. $\mathrm{Bu}$ yazılımlar, özellikle 70'li yılların bireylerinden çağımız gençlerine geniş bir hedef kitleye sahiptir. Teknoloji ilerledikçe oyun yazılımları ve oyun cihazlarının üzerine olan ilgi dramatik bir şekilde artmıștır. Ayrıca bu yazılımlar günümüzde sabit bir ekran başında olma zorunluluğundan uzaklaşıp artık mobil cihazlarda bile karşımıza çıkmaktadır. Mobil teknolojiler denildiğinde, mobil cihazlar, mobil işletim sistemleri ve mobil uygulamalar gibi sistemler de akla gelmektedir. Bir mobil teknoloji olan mobil uygulamalar, yaygın olarak kullanılan akıllı telefon ve tablet bilgisayar gibi cihazlar için geliştirilen yazılımlardır (Gümüş Ç., Tengirşen A. $2020 \mathrm{~s}: 392$ )

Oyun sektörü söz konusu olduğunda anlaşılması kolay olan oyunlar her zaman daha geniş kitlelere hitap etmiştir. Buna oyunların artık taşınabilir cihazlarda olabilmesi de eklenince oyun sektörü alanındaki büyüme hızla ilerlemiș ve günümüze kadar gelmiştir. Geçmişten bugüne hızlı bir biçimde gelişen oyunlar birçok türünü hayatımıza katsa da hala popülerliğini yitirmeyen ve en çok tüketilen oyun türlerinden biri platform oyunlarıdır. Oynanış şekli ve mantığı yaklaşık 50 yıldır büyük bir değişim göstermeyen bu türün hala popüler olmasının nedenlerinden biri de çok renkli ve sanatsal yaklaşım içeren illüstrasyon uygulamaları barındırmasıdır. Bu fantastik dünyaları daha da renkli kılan dijital illüstrasyonların günümüzde ekran üzerinde oluşturulmuş örneklerini çeşitlendirilmiş ve geliştirmiştir.

Bilgisayar oyunları icadından bu yana büyük kitlelere hitap etmiş ve çeşitli kitleler tarafından benimsenmiştir. Günümüzde oyun sektörü gerek teknoloji gerekse de ekonomik açıdan çoğu sektörün gelişmesine de destek olmuştur. Bilgisayar oyun endüstrisi her geçen gün büyümekte ve genişlemektedir. Sektörün son yıllarda satışa dayalı olarak ABD'deki film ve kayıt endüstrileriyle bile rekabet edebildiği gözlemlenmiştir (Qin $\mathrm{H}$. Rau P. P. ve Salvendy 2009 s:108). Oyunlar dünya üzerinde donanımların ve yazımların gelişmesi ile gelişmiş, buna zıt olarak yazılımların ve donanımların da gelişmesine neden olmuştur. Oyunların aynı zamanda insan gelişimi üzerinde de etkisi vardır. İster eğitim amaçlı tasarlanmış ya da bu amacı gütmeden tasarlanmış olsun, doğru tasarlanmış ise bir oyunun insan gelişimine olumlu yönde katkısı olduğunu söylemek mümkündür. Kimi video oyunlarının, faydalı olduğu ve birçok alanda önemli etkileri olan güçlü bir öğretici olduğu açıktır (Prot S., ve diğerleri 2012 s: 647). İnsanların dijital oyunlarla tanışma süreci genellikle genç yaşlarda olmuştur. Buna bağlı bir biçimde video oyun dünyası çocukları daha çabuk etkisi altına almaktadır. Bunun başlıca nedeni ise oyunların renkli dünyasıdır. Fakat bu tanışma yaş ilerledikçe azalabilmektedir. Ekteki tabloda ileri Amerika'da 2019 y1lındaki yaşlara göre oyun oynama istatistikleri verilmiştir. Tabloya göre 35 ve sonrası yaşlar için bilgisayar oyunu oynama istatistiğinin dramatik şekilde düştüğü görülmektedir.

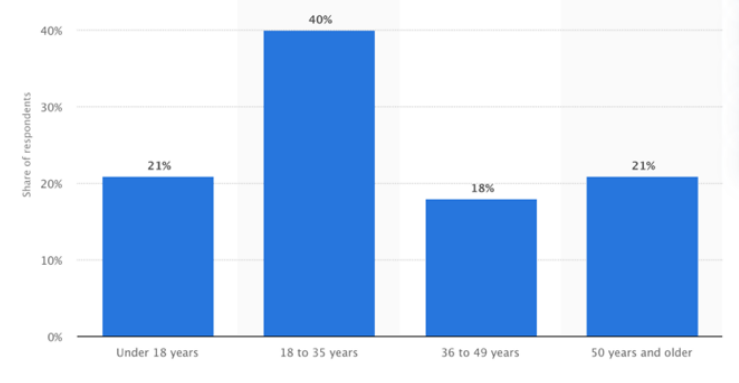

Şekil 1- 2020'de Amerika Birleşik Devletleri'ndeki video oyunu oyuncularının yaş dağılımı (statista.com)

İster genç ister ileri yaşlarda olsun insanların video oyunlarına olan ilgilisi yıllardır yüksek seviyede olmuştur. Video oyunları, 1970'lerin başında basit ping pong ve ilk ev video oyun konsolu Magnavox Odyssey'nin piyasaya sürülmesiyle başlamıştır (americanhistory.si.edu).

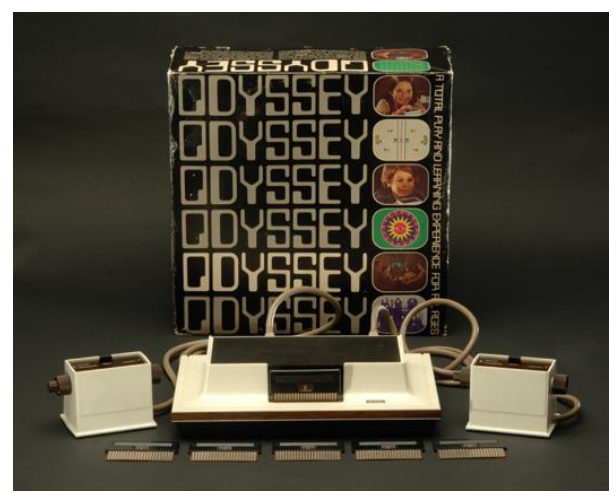

Resim 1 - Magnavox Odyssey (americanhistory.si.edu).

Ping Pong oyununun ev versiyonu, en az kollu makine versiyonu kadar başarılı olmuştur. Atari firması sadece 1975 'te 150.000 adet Ping Pong oyunu içeren konsol satmıştır (www.si.edu). 70'li yıllarla son kullanıcinın evine girmeye başlayan oyunlar siyah bir arka plan üzerinde beyaz piksellerden biraz daha fazlasıydı, ancak bu kadar geri bile olsalar bile birinci şahıs nişancı da dahil olmak üzere gelecekteki çok sayıda oyun türüne ön ayak olmuşlardır. İlgi üzerine geçen 10 yıl boyunca oyunlar ve konsollar hızlı bir şekilde gelişme göstermeye başlamıştır. Fakat bu gelişme içinde gelişmemiş grafikler herhangi bir sanatsal yaratıcılığın ortaya çıkmasına engel olmuş ve özellikle döneminde tüm oyunlar birbirine yakın görünmeye başlamıştır.

1980'lerin başında Nintendo Entertainment System'in piyasaya sürülmesiyle, bu estetik kaygılar yerini biraz sanatsal dokunuşlara bırakmaya başlamıştır. Grafiksel olarak bir devrimden söz edilemese de renkler ve çeşitlilik farklı yaklaşımlara izin verebiliyordu. Gelişen cihazlarla birlikte hikâye anlatımı ve müziğin oyunlarda daha önemli roller oynamaya başladığı görüşmüş̧ür. Bu dönemde ilerde kült bir oyun olacak olan Donkey Kong, Nintendo'da çalışan sanatçısı Shigeru Miyamoto'nun elinden çıkmıştır. (nintendo.co.uk).

1990'lara birlikte oyun sanatı çoğu türde gelişmeye çeşitlenmeye başlamıştır. Dönemin ana sistemleri olan Super Nintendo ve Sega Genesis, önceki nesillere göre daha hızlı ve 
daha ayrıntılı grafikler sunarken, her iki şirket de dünya çapında yaygınlaşmaya başlamıştır (computinghistory.org.uk). Oyunları depolamak için yeterli alan sorunu CD'ler ile aşılmaya başlanınca daha geniş veri alanı birçok gelişime ön ayak olmuştur. Sesler, müzikler sinematik geçişler bunlardan sadece birkaçıdır. Konsollar ve kişisel bilgisayarlar zamanla gelişmiş depolama hususunda DVD ler ve daha sonra da BlueRay teknolojisi CD'lerin yerini almıştır. Blu-ray, $C D$ ve daha sonrasında DVD'den sonra üçüncü nesil kompakt disk teknolojisini temsil etmektedir (britanica.com). Pikseller ve depolanabilecek sayısal verilerin sınırları aşıldıkça oyunlar da daha yüklü ve daha gelişmiş olmaya devam ettiler. Grand Theft Auto oyunundaki devasa sanal şehir manzaralarını keşfetmekten Half-Life oyunundaki korkutucu anlara kadar, oyuncular artık bir oyunun görsellerine daha çok kapılıp, zamanla kendilerini oyuna daha ait hissetmeye başladılar. Konsolların yanında masaüstü bilgisayarlarda da eş zamanlı gelişen gelişmeler özellikle ekran kartı bileşenlerini işin içine dahil ederek kimi zaman konsoldan iyi kimi zamanda konsol gücünde görüntüleri kullanıcılarına sunabilmişlerdir.

Enformasyon çağı sürecinde bireyler karşılaştıkları her yeniliğe bire bir şahit olmuş ve bundan sonra gelebilecek yeniliklere de adapte olmada zorluk çekmemiştir. Ama bu süreçte özellikle oyun içeriği tüketiminde insanların vazgeçemediği bir tür var ise o da 2 boyutlu düzlemde karakter merkezci ve genelde bir hikâye örgüsüne sahip olan platform oyunlarındır. "Platform" veya "platform oyunları", çoğunlukla oyuncu tarafından kontrol edilen ve engellerden kaçınmak ve / veya düşmanları yenmek için koşan ve zıplayan bir karakter etrafında dönen oyunlardır. Platform genellikle aksiyon oyunlarının bir alt türü olarak sınıflandırılır ve ilk oyun türlerinden biri olarak kabul edilir (Minkkinen T. 2006 S:2).

\section{Platform Oyunları Tarihi}

\section{1. İlk Yıllar}

Çağlar boyunca çoğu oyun ya da oyuncu için jenerasyon tanımlaması dönemi anlatmak için belirli bir unsur olmuştur. Paceman jenerasyonu, Super Mario jenerasyonu, Half-Life jenerasyonu, Uncharted jenerasyonu, Wolfenstein jenerasyonu ve hatta PUBG jenerasyonu bile bir jenerasyon olarak tanımlanabilir. Jenerasyonlar arası eskimeyen tek tür platform oyunlarıdır. Günümüze kadar popülaritesini koruyan farklı birçok tür olsa bile, platform oyunları muhtemelen onlarca yıl boyunca en çok sevilen oyun türü olmuştur. İster Mario, ister bu nesilde Gris olsun platform oyunları mekanik oynanış açısından basit olsalar da hala popülerliklerini korumaktadırlar.

Tarihini incelediğimizde Universal firması tarafından geliştirilen 80'lerin arcade oyunu Space Panic, platform türünü popülerleşmesine ön ayak olmuştur. Space Panic oyunundaki karakterlerde zıplama özelliği yoktu ama oyuncular aşağı yukarı inmek için merdivenleri kullanabilmekteydi. Bu dönemdeki platform oyunlarında sağa sola ekran hareketi yoktu ve ekran yani zemin sabitti. Bu alanda devrimi başlatan ise Donkey Kong oyunu olmuştur. 1981'de Nintendo, tüm zamanların ilk gerçek platform oyunu olarak kabul edilen Donkey Kong'u piyasa çıkartmıştır (Rogers 2018). Oyunun başarısı, devam oyunları Donkey Kong Jr., Donkey Kong 3 ve sonunda günümüzde hala birçok oyun cihazında yeni yaklaşımlarını gördüğümüz gördüğümüz Mario Bros ile yeni bir oyun dizisi ile devam etmiştir. Seri sonrası birçok benzeri oyun çıksa da o dönemki konsolların kapasiteleri çoğu yeniliğe ya da geliştirmeye izin vermemekteydi. Tür için İngilizce 'Hop ve bop' denmekteydi. Bu deyim, düşmanları yenmek için düşmanlara atlamaktan kaynaklanmaktadır. Super Mario Bros ve Sonic the Hedgehog gibi en kült platform oyunlarının birçoğu da bu türe aittir. (Boutros $2006 \mathrm{~s}: 1$ )

\subsection{Yana Kaydırma Dönemi}

1981 yılında geliştirilen bir oyun olan Jump Bug tek zeminlik dönemden kaydırmalı döneme geçen ilk oyunlardan olmuştur. Oyun esnasında kullanılan zemin durağan değil ekranın kayması ile daha geniş bir alanda seyrediyordu. Bir diğer yaklaşım da ColecoVision tarafindan geliştirilen ve 1983 'te piyasaya sürülen, kaydırma seviyelerine sahip oldukça basit bir platform olan Quest for Tire oyunuydu. 1984 yılında geliştirilen Pac-Land oyunu ise arka planın ön planlardan daha yavaş hareket etmesini sağlayarak derinlik etkisi oluşturmayı başarmıştır. Bu paralaks özelliği türün gelişimine katkı sağlamıştır (strategywiki.org).

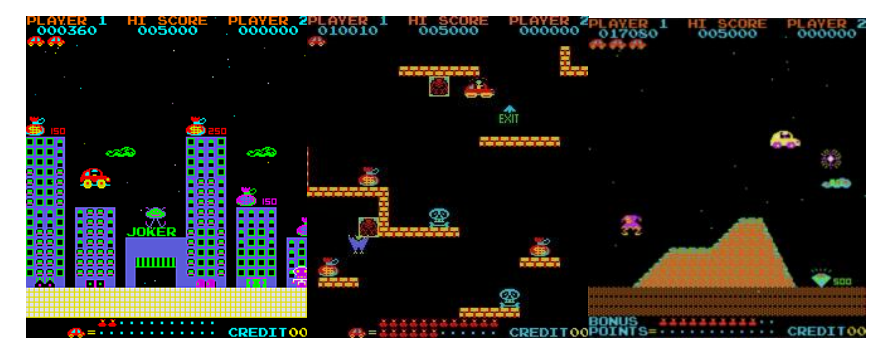

Jump Bug (archive.org)

1985'te Super Mario Bros sonunda NES sistemlerde oynanabilir hale getirilmiştir. Mario çıktığı dönemde günümüzde bile halen var olan seviye yaklaşımları, düşman yazılımları, bölüm sonu savaşları, gizli bölümler ve güçlendirmeler gibi birçok yeniliği getirmiştir. Dönem sistemlerinin sınırları bu yöndeydi ve Mario bu halde bile çoğu gelişmeye ön ayak olmuştur. Mario oyununun başarısı yanında Mega Man ve Metroid gibi diğer önemli oyunlar da dönemde etkisini göstermiştir. Dönem içerisinde rekabet ve cihazların yapabilirlikleri arttıkça farklı kullanımlar ve platformların sınırları zorlanmaya başlamıştır. Nintendo'un Mario oyunundaki başarısı hızla artarken rakip firma olan Sega Sonic oyununu geliştirmiştir. Dönemde konsollarla birlikte PC'lerin de oyun başarımı artmaktaydı ve bağımsız firmaların ürünlerinden olan ve bir dönem oldukça ses getiren Commander Keen kendinden söz ettirmeye başlamıştı. Platform oyunlarının PC'deki başarısı daha sonra benzeri oyunlar olan Duke Nukem ve Jazz Jackrabbit gibi oyunların önünü açmıştır (Fox 2016).

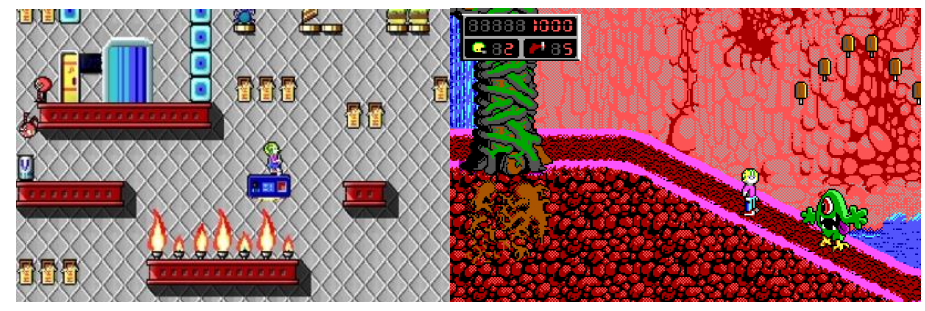

Commander Keen (dosgames.com) 


\subsection{Konsollarda 16-Bit Dönemi}

16 bit dönemi tarihin en iyi platform oyunların ortaya çıkmasına neden olmuştur. Dönemim cihazlarının kapasitesi Capcom'un Mega Man oyunun, Super NES'de daha geliştirilmiş Mega Man X serisinin ortaya çıkarabilmesine izin vermiştir. Super Metroid, Rayman, Super Mario World 2: Yoshi's Island ve diğer klasikler yine bu dönemde ortaya çıkmıştır. Dönemde platform oyunlarının ön göremediği fakat hızla yayılan 3D furyası birçok oyuncu için moda haline gelmeye başlamıştır. Bu döneme ayak uydurmaya çalışan bir firma, 3D grafikler kullanan ancak eylemi 2D bir düzlemde sunan 2.5D yaklaşımı ile ürünler ortaya çıkartmıştır. Bu dönemin en önemli eserleri Sega'nın Clockwork Knight, Pandemonium ve Klonoa olmuştur.

\subsection{Boyutlu Platformlar Çağı}

İki boyutlu platform oyunları giderek daha fazla 3D oyunlarla değiştirilse de, bu tür hala birçok insan tarafindan sevilmektedir (Wiering M., Achten P. ve Plasmeijer R. 2000 s:1). Gerçek anlamda 3 boyutlu olan ve platform oyunu olarak geliştirilen ilk oyunlardan biri 1996 yılında geliştirilen ve Nintendo 64 cihazları ile ortaya çıkan Super Mario 64 oyunu olmuştur (Stanton 2015). Kullanıcılarına değişik gelse de oynanabilirlik iyi düzeyde olduğu için kullanıcılar tarafından benimsenmesi kolay olmuştur. Super Mario 64'ün başarısını Banjo-Kazooie ve Donkey Kong 64 oyunları izlemiştir ve 3 boyutlu platform oyunu tarzı yavaş yavaş kendini kabul ettirmeye başlamıştır. Dönemin günümüze yansıyan oyunlarından örnek vermek gerekirse en önemli örneği Tomb Rider gibi yaklaşımlardır.

\subsection{Yeni Yaklaşımlar}

Y1llar geçtikçe üretici tekeli sadece Nintendo-Sega tekelinden çıkmış ve pazarda PlayStation ile kişisel bilgisayarlar da boy göstermeye başlamıştır. Özellikle Sony cephesinde PlayStation2 için geliştirilen Sucker Punch, Sly Cooper; Naughty Dog, Jak and Daxter, Ratchet and Clank gibi oyunlar PlayStation'un ün kazanmasına sebep olmuştur.

Dönem içerisinde Sega, popülerliğini yitirirken son girişimi Sonic 3D Blast, farklı bir 3D platformer girişimi olmuştur. Dönemde Sega'nın geliştirdiği diğer oyunlardan olan Nights Into Dreams akillica bir Sega Saturn oyunuydu, ancak ne kadar iyi tasarlanmış olsa da Sega'nın başarısız olmasına engel olamamıştır (Stuart 2015).

Gelişmelere cevap olarak 1999'da Sega, ilk 128-bit ev konsolu olan Dreamcast'i piyasaya sürdü. Konsol ile birlikte gelen Sonic Adventure bir çıkış oyunuydu. Devamında gelen Jet Set Radio, Rayman 2 ve Sonic Adventure 2 gibi oyunlar Sega'nın tekrar pazarda adını duyurabilmesine neden oldu (Werner N. 2018). Fakat devamında gelen Satürn'ün başarısızlığı ve Sony'nin artan ünü Sega'nın büyük kayıplar yaşamasına neden oldu şirket ve şirket konsol geliştirmeyi bırakmıştır. Nintendo ise, yeni GameCube konsolu ile üzerinde çalışıyordu ve 2002'de yenilik olarak sadece Super Mario Sunshine piyasaya çıkmıştır.

\subsection{Yüksek Bütçeli Oyunlar Dönemi}

İnsanların oyunlar üzerindeki beklentisi beraberinde daha karmaşık konsolları ve yazılımları getiriyordu. Ayrıca bu konsollar bir yandan daha çok eve girerken bir yandan da artan donanım ve yazılım maliyetlerini beraberinde getiriyordu. Ancak insanlar bu cihazlar benimseyerek birçok yüksek bütçeli oyunun satışına ön ayak olmuşlardır. Nintendo, bu dönemde hareket kontrolleriyle Wii'yi tanıtmıştır ve konsol için çıkan platform oyunlarından olan Super Mario Galaxy serisi seviyeleri ve oynanışı ile adından söz ettirmiştir (britannica.com). PlayStation tarafında özellikle PlayStation3'ün çıkması ile birlikte Future serisi adından söz ettirmeye başlamıştır. Dönemde yüksek bütçeli firmalardan olan Electronic Arts Mirror's Edge'de ilk kişi platform oyununu piyasaya sürmüştür. Bu platform yaklaşımı türe yeni bir soluk getirse de devamı gelmemiştir (Suttner 2008).

PlayStation 3 yaygınlaştıktan sonra Sony, oyuncuların kendi küçük deneyimlerini yaratmaları için kapsamlı bir araç setine sahip LittleBigPlanet'i piyasaya çıkartmıştır. Ayrıca dönemde popülerliğini geliştiren Lara Croft serisi de bir platformu andıracak özellikleri ile geri dönmüştür. Sega bu dönemde halen kan kaybetmeye devam etmiştir ve yeni nesil Sonic oyunları da buna engel olamamıştır (Stuart 2015).

\subsection{Geçmişin Geri Dönüșü}

Yüksek bütçeli oyunlar döneminde bir yerlerde, çok sayıda bağımsız geliştirici de eski 2D platformlarına oynanış tarzını yeniden yorumlayarak tasarladıkları oyunları birçok platformda piyasaya sürmüştür. Jonathan Blow'ın Braid oyunu, Phil Fish'in Fez'i, Team Meat'in Super Meat Boy'u ve Playdead'in Limbo, oyunları bağımsız gelişimi bir bütün olarak popüler hale getirmişlerdir. Küçük stüdyolar yaratıcı fikirlerle büyük firmalara rakip olabileceğini göstermiş ve iyi bir oyun için büyük bir stüdyo gereksinimine gerek olmadığını ortaya koymuşlardır.

Dönemde sayısız bağımsız geliştirici unutulmaz eski tarz 2B platform oyunları piyasa çıkartmaktaydı. Owlboy, Hollow Knight, Axiom Verge, Giana Sisters, Inside, Spelunky, Cuphead ve çok daha fazlası, oynanabilirliği ve grafik seviyesi yüksek oyunlar olarak piyasaya çıkmışlardır.

Teknoloji gelişse de bu basit düzlemdeki platform oyunlarına olan ihtiyaç asla bitmeyecek gibi görünmektedir. Platform oyunları yıllar boyunca gelişmiş veya çoğalmış olsa da yine de eskimeyen bir tür olarak başarısını sürdürmektedir. Gelecekte ne yöne gideceği bilinmese de özellikle mobil cihazlar ile popülerliklerini arttırarak varlıklarını sürdürmektedirler.

Oyun gibi dijital üretim için geliştirilen ve profesyonellerin yanı sıra son kullanıcıların evine kadar giren içerik üretebilen bilgisayarlar 2000'li y1llarla birlikte daha kolay edinilebilir hale gelmiştir. Bu cihazlar gerek ergonomi gerekse de taşınabilirlik açısından da çeşitlenmiş ve yaygınlaşmıştır. Bu yaygınlaşma beraberinde çoğu alanda olduğu gibi dijital sanat alanında da etkilerini göstermiştir. Bu dijital sanat alanlarının başında dijital illüstrasyon gelmektedir. Kâğıt ekrana, kurşun kalemden tablet kalemine dönüşen bu süreç beraberinde sanatçılar için yeni olanaklar ve sınırların aşılması yönünde sonuçlar getirmiştir (creativebloq.com).

Teknolojinin gelişmesi ekranların, oyunların ve yazılımların karmaşık hale gelmesine neden olmuştur. Günümüzde teknolojinin gelişmesi, görsel iletişim tasarımı camiasına görüntüleri daha çok işleyebilme imkanı vermiş ve görseller dünyayı kuşatmıştır (Çeken B., Arslan A. A. 2016, s:508) Bu 
bağlamda oyun yazılımlarının ve oyunların ilk çıktığı cihazların görüntülerine baktığımızda oldukça yavan ve tatsı göründüğünü bilmekteyiz. Dönemin oyunlarının bu denli yavan olmasının nedeni dönemin cihazlarının başarımı ile doğru orantılı olabilmekteydi. Sanatçı çok iyi dijital bir illüstrasyon ya da oyun arayüzü geliştirebilecek olsa bile o zamanın teknolojisi buna izin vermemekteydi. Ayrıca dijital çizim aracı olarak girdi birimi bir kalem değil çoğu zaman bir klavye ya da yazılım olmuştur. Fakat günümüze gelindiğinde dijital sanatçılar artık ekranlar üzerinden birebir çizim yapabilmektedirler. Bu gelişim illüstrasyon sanatı alanına da etkisini göstermiş, alanda birçok yeni sanatçı ve türün çıkmasına neden olmuştur. Oyun dünyası 3 boyutlu yaklaşımlar ve ileri düzey gerçekçilik üzerine koşsa da özellikle de günümüzde hala eskimeyen ve varlığı sürdüren platform oyunlarındaki illüstrasyonların gelişimi türün halen ayakta kalmasına en büyük etkenlerden biridir. $\mathrm{Bu}$ bağlamda bu araştırma özelinde incelenen Hollow Knight Gris Cuphead, Ori and the Blind Forest oyunlarındaki güçlü illüstrasyon teknikleri değerlenirmiştir. Araştırma bazında bazı oyunlar 3 boyutlu öğeler barındırsa da tam 3 boyutlu oyun olarak geçmemekte ve özellikle mekanların tasarımları 2 boyutludur.

\section{Araştırma}

\subsection{Hollow Knight}

Hollow Knight, aksiyon macera dalında geçen bir platform oyunudur. Oyun, platform alt türü olarak Metroidvania türündedir. Metroidvania, Castlevania: Night Symphony of the Night ve Metroid'de bulunan mekaniğin bir kombinasyonunu içeren video oyunlarının tümüne verilmiş isimdir ve platform oyun türünün alt türü olarak tanımlanmıştır (screenrant.com). Hollow Knight Team Cherry tarafından geliştirilip 2017 yılında dönemin birçok oyun platformunda yayınlanmıştır. Hollow Knight oynarken çeşitli böceklerin yaşadığı krallık geçmeli, oyuncu Knight Hallownest ile seyahat edilmeli, bölüm sonu canavarları ile savaşmalı ve krallığın gizemlerini ortaya çıkarırken ilerlemek için yeni yeteneklerin kilitleri açılmalıdır.
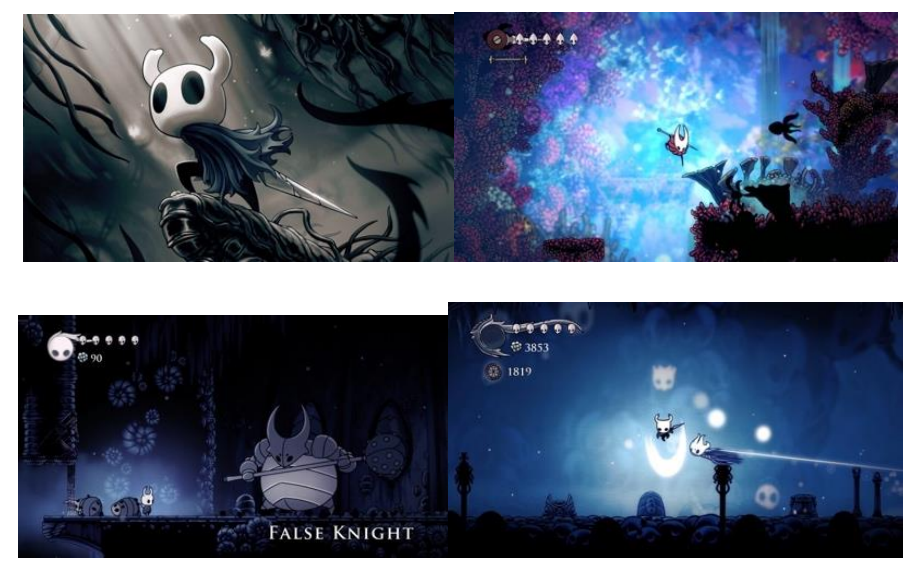

Hollow Knight Ekran Görüntüleri

Oyun arayüz tasarımı incelendiğinde 2 boyutlu düzlemde ve karanlık bir evrende geçtiği görülmektedir. Merkezde bulunan karakterin karanlık veya açık ortamlarda belirgin olabilmesi için kendisi beyaz, kontur çizgisi için siyah kullanılmıştır. Bu sayede karakterin önemli hareketler esnasında oyuncunun gözünden kaçmaması sağlanmıştır.

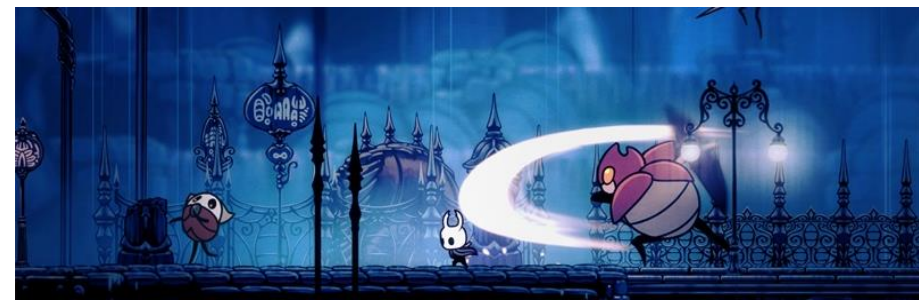

Hollow Knight Ekran Görüntüsü

Oyunun bölüm tasarımları ve zeminleri incelendiğinde zeminde flu görünen alanlar derinlik oluşturabilmek için bulanıklaştırılmış. Paralaks efektini uluşturan ikinci zemin ise her ne kadar net görünse de hareketli karakterler kadar net kullanılmamıştır. Oyunun çok çeşitli gibi görünmeyen renk paleti soğuk bir etki yaratsa da oyunun hikayesine uygun olarak seçilmiştir. Bu tarz bir illüstrasyon yaklaşımı flat (düz) tasarım diline benzetilmiştir.

\subsection{Gris}

Gris, İspanyol bağımsız geliştirici Nomada Studio tarafından geliştirilen ve Devolver Digital tarafından yayınlanan bir platform-macera oyunudur. 2018 yılında önce konsollara daha sonra da mobil olarak yayınlanmıştır. Oyunun hikayesi yoğun olarak keder ve geçmiş kayıplar üzerinedir. Oyunda oynadığımız Gris adındaki kadın bir karakter. Dünyasını araştırırken karakterin yapabildiği özellikler gelişmekte ve dünya daha renkli bir hal almaktadır. Hikâye hakkındaki yorumu çoğu zaman oyuncuya bırakan oyun çoğu metaforu bünyesinden barındırmaktadır.

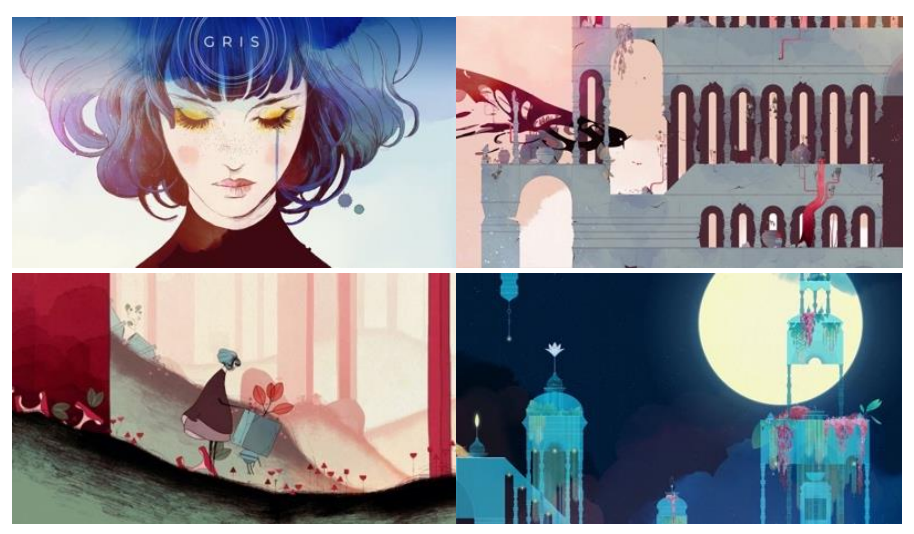

Gris Ekran Görüntüleri

Gris oyunu görsel tasarım yönünden çok güçlü bir oyun olarak karşımıza çıkmaktadır. Oyun platform oyunlarına bugüne kadar görülmemiş estetik ve sanatsal çizim yaklaşımlarını içinde barındırmaktadır. İnce çizgiler ve suluboya stilinde naif renk dağılımları vardır. Oyundaki olabildiğince estetik karakter hareketleri bir platform oyununda daha önce görülmemiz bir yaklaşımı gözler önüne sermiştir. Bu yaklaşım birçok oyun sever tarafindan beğenilmiştir. Oyun oynanışı çok şeyler vaat etmese de kullanılan sanatsal etki ve illüstrasyonlar oyunun oynanışının önüne geçmiştir. 


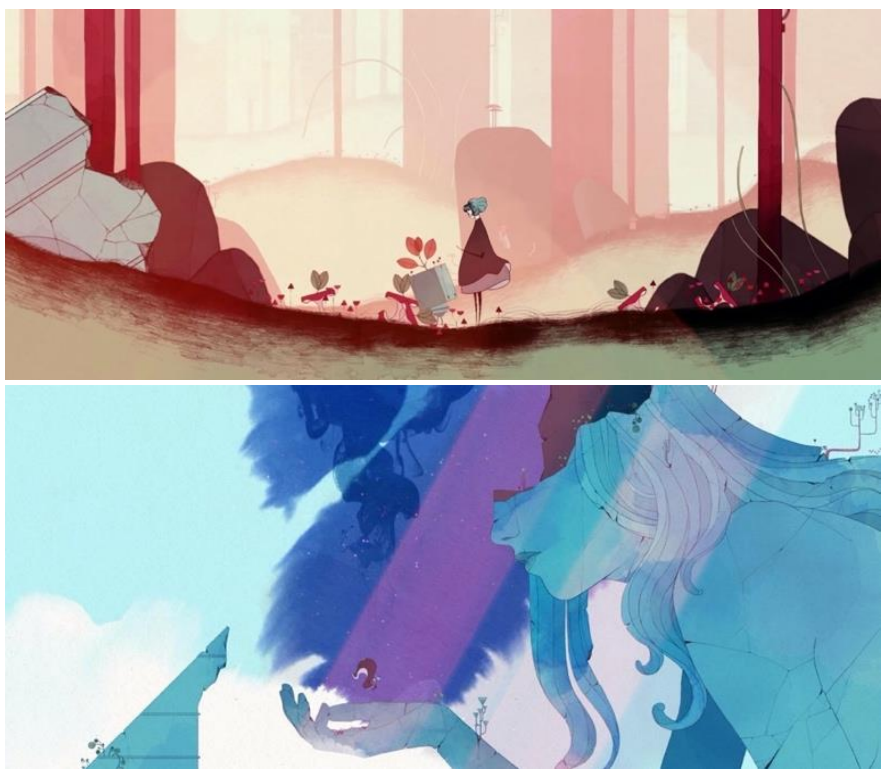

Gris Ekran Görüntüleri

Gris tasarımı üzerine her zaman daha çok konuşulmayı hak eden bir yaklaşım ortaya koymuştur. Çoklu katman renk dağılımı sergileyen animasyonları ve bu sulu boya dökülme efekti şeklinde yayılan renk geçişleri Gris'i çoğu benzerinin önünde bir yere konumlandırmaktadır. Sergilediği sanatsal yaklaşım bugüne kadar çoğu platform oyununda görülmemiş ve yenilerine ilham kaynağı olmuştur. Dijital sanatın sanat olarak benimsenmesi yönündeki tartışmalara oyun içinde sanat kavramını da ekleyen Gris, dijital illüstrasyon sanatının nerelerde ne şekilde kullanılabileceğine dair önemli bir örnek olarak karşımıza çıkmaktadır.

\subsection{Cup Head (Don't DealWith the Devil)}

Cuphead Studio MDHR tarafından geliştirilen ve yayınlanan bir platform oyunudur. İlk olarak 2017 Xbox'da ve sonrasında birçok platforma çıkmıştır. Koş ve ateş et tarzında bir oynayış stili olan oyunda konu Cuphead ve kardeşi Mugnan'1n macerası üzerine gelişmektedir. Karakterler şeytana olan borçlarını düşmanlarla savaşarak ödemektedir ve kurgu bu şekilde ilerlemektedir. Oyun zor oynanışı ve özgün konsepti o kadar beğenilmiştir ki dizi olarak da Netflix tarafından uyarlanması düşünülmektedir.

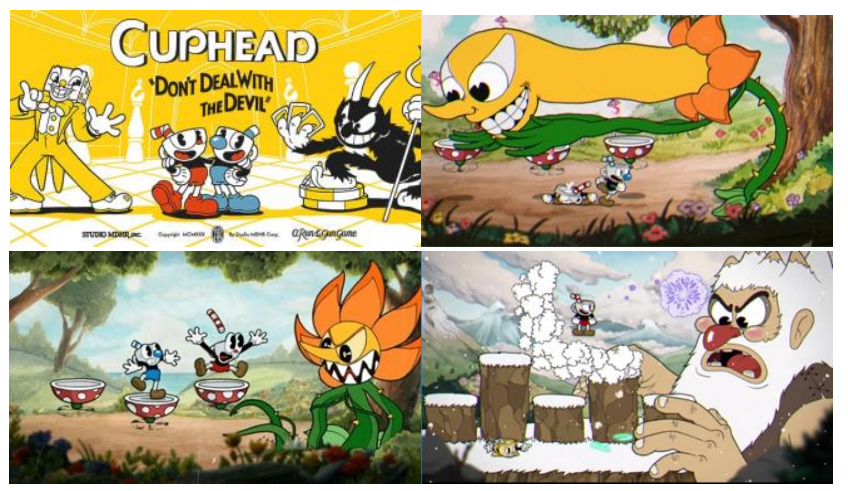

Cup Head Ekran Görüntüleri

Oyun, 1930'lu yılların efsanevi Fleischer ve Walt Disney animasyon sitili olan hortum bacak animasyon stilinden ve hareketlerinden esinlenerek tasarlanmıştır. Özetle çizgi film diyebileceğimiz tarzda hazırlanmıştır. Düz ve sınırlı sayıda renkle boyanmış haraketli sahneler. Hareketli sahneler üzerinde kontur çizgileri ve detaylı resmedilmiş zemin çizimleri oyunun illüstrasyon karakteri olarak tanımlanabilmektedir. Oyun konseptindeki çizgi film anlayışı zeminleri bir Rönesans tablosu gibi resmederken karakterleri tamamen basit halde görselleşmiştir.

\subsection{Ori and Blind Forest}

Ori, Moon Studios tarafından geliştirilen ve Microsoft Studios tarafindan yayınlanan bir platform-macera Metroidvania oyunudur. Oyun ilk olarak 2015 yılında piyasaya çıkmıştır. Oyuncular küçük beyaz karakter olan Ormanın Ruhu Ori'yi kontrol etmektedir. Oyuncular Ori'yi kontrol ederek platformlar arasında hareket etmek ve bulmacaları çözmekle görevlidir.

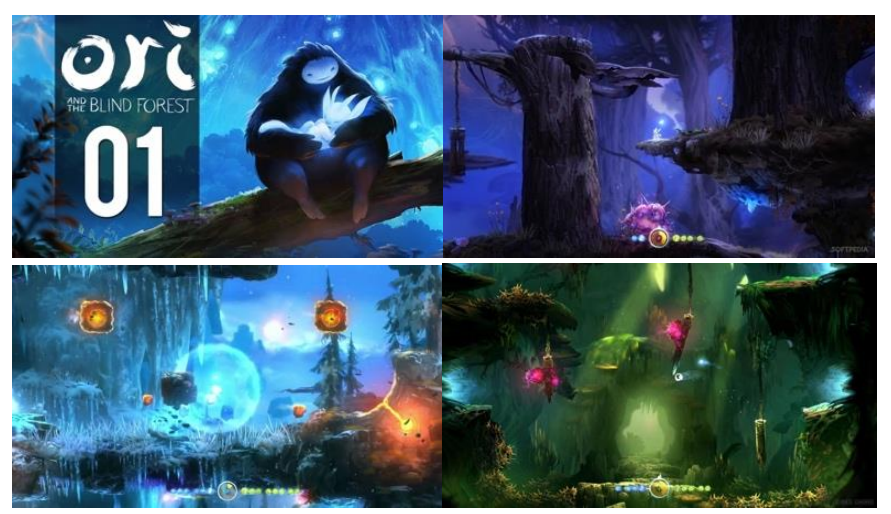

Ori platform oyunu olarak karmaşık animasyonlar ve 3B destekli karakter animasyonları kullanmaktadır. Her ne kadar 3 boyutlu bir yaklaşımmış gibi görünse de oyunun çok katmanlı ve çok renkli yapısı 2 boyutlu olarak resmedilmiş ve çeşitli tekniklerle 3 boyutlu gibi gösterilmeye çalışılmıştır. Oyunun çoğunluğunda kullanılan bu paralaks efektleri ve derinlik göstergesi olan çizimler oyuncunun kendini oyuna daha iyi şekilde adapte olmasını sağlamaktadır. Ori tasarımı içerisinde güçlü dijital illüstrasyon teknikleri barındırmaktadır. Işık efektleri parlamalar yansımalar dijital illüstrasyon sanatının sınırlarını zorlamakta hatta türe yeni yaklaşımlar katmaktadır.

\section{Sonuç}

Dijital illüstrasyonlar bir sanatçının bilgisayar desteği ile oluşturduğu çizimler olarak özetlenebilir. Kurşun kalem, boya ve kâğıt gibi fiziksel dünyanın malzemelerinden farklı olarak dijital illüstrasyonlar sayısal veri olarak ekranlarda, fiziksel dünyalarda ise baskı olarak görüntülenebilmektedir. Dijital cihazların kullanımı ve hayatımızdaki yeri arttıkça bu cihazlar içerisindeki içerik ihtiyacı da artmaktadır. Söz konusu dijital dünyadaki 
oyunlar olduğunda oyunların renkli dünyasını oluşturmak için çizimlerin ve renklerin kullanılması neredeyse bir zorunluluk haline gelmektedir. Dijital dünyadaki çizim yani dijital illüstrasyon çoğu sanatçısını daha özgür kılmaktadır. Bu özgürlük yapılan hataların geri dönüşlerinin olabilmesi gibi kullanılan tekniklerin, firça darbelerinin ve karışık medya tekniklerinin oluşturulması hususunda uçsuz bucaksız denklemleri beraberinde getirmektedir. Geleneksel illüstrasyon yöntemleri ile oyun arayüzleri hazırlamak ve bunu dijital dünyaya aktarmak mümkündür. Fakat gelişen hızlı teknoloji ve tüketim, sanat alanının bu yoğun, dikkat isteyen, hata kabul etmeyen ve esnek olamayan tekniğini -her ne kadar daha özgün ve sanatsal olsa daartık tercih etmemektedir. Yeni illüstrasyon yöntemlerini kullanmak, geleneksel illüstrasyon yapma yönteminden çok daha hızlıdır (Coleman C. O., 2003, s:1). Bu çalışma özelinde yapılan araştırmada amaç geleneksel ya da dijital illüstrasyonu karşılaştırmak değildir. Aksine iki alanında kullanım alanlarının artık ayrıştığını ve iki alanında kendi özelinde yer bulduğunu göstermektir. Gelişmelerin incelenmesini ise özellikle dijital illüstrasyon alanında sınırlandığını sergilemektir. İncelenen oyunlar göstermiştir ki her geçen gün gelişen dijital illüstrasyon teknikleri ile sanatçılar, oyun ve eğlence sektöründe yaptıkları işler ile büyük kitleleri etkilemeye başlamıştır. Bu bilgiler ışı ğında incelendiğinde dijital illüstrasyon günümüz sanat yaklaşımları arasındaki yerini daha özgün yaklaşımlar ve tekniklerle her geçen gün geliştirmektedir.

\section{Kaynakça}

Britannica Nintendo Wii electronic game console https://www.britannica.com/topic/Nintendo-Wii Erișim Tarihi: 20.07.2020

Blu-Ray Disc Technology https://www.britannica.com/technology/Blu-ray Erişim Tarihi: 11.07.2020

Magnavox Odyssey Video Game Unit, 1972 https://americanhistory.si.edu/collections/search/object/nma h 1302004 Erişim Tarihi: 13.05.2020

Boutros, Daniel. 2006. A Detailed cross-examination of yesterday and today's best-selling platform games http://www.gamasutra.com/view/feature/1851/a_detailed_cr ossexamination of . php Erişim Tarihi: 25.06.2020

Computer Game Narrative, Intl. Journal Of Human-Computer Interaction, 25(2), 107-133, 2009

Coleman C. O., 2002 "Digital inking": how to make perfect line drawings on computers, Institut für Systematische Zoologie, Museum für Naturkunde, Berlin, Germany

Çeken B. ve Arslan A. A. İmgelerin Göstergebilimsel Çözümlenmesi "Film Afişi Örneğì" Bayburt Eğitim Fakültesi Dergisi, Y11: 2016 Cilt: 11 Sayı: 2

Digital illustration https://www.creativebloq.com/computerarts/digital-illustration-11069638 Erişim Tarihi: 12.06.2020

Fox K. 2016 Game Cloud Commander Keen: The Complete Collection Retrospective Review

https://gamecloud.net.au/featured/commander-keen-thecomplete-collection Erişim Tarihi: 15.06.2020

Gümüş Ç., Tengirşen A. 2020, Yetişkinlerin Psikolojik Destek Almasına Yönelik Mobil Uygulama Tasarımı, Social Mentality and Researcher Thinkers Journal
Metroidvania Meaning

Screenrant https://screenrant.com/metroidvania-meaning-definitionexplained/ Erişisim Tarihi: 30.07.2020

Minkkinen T. 2016, Basics of Platform Games, Kajaanin Ammattikorke Akoulu University of Applied Sciences

National Museum of American History, The Father of the Video Game: The Ralph Baer

Nintendo

History https://www.nintendo.co.uk/Corporate/NintendoHistory/Nintendo-History-625945.html\#1980 Erişim Tarihi: 25.06.2020

Prot S., McDonald K. A., Anderson C. A., Gentile D. A. 2012 Video Games: Good, Bad, or Other? Department of Psychology, Iowa State University, W112 Lagomarcino Hall, Ames, IA 50011-3180, USA 647-658

Pac-Land 2020 Strategy Wiki https://strategywiki.org/wiki/PacLand Erişim Tarihi: 12.05.2020

Prototypes and Electronic Games Video Game History https:/www.si.edu/spotlight/the-father-of-the-video-gamethe-ralph-baer-prototypes-and-electronic-games/videogame-history Erişim Tarihi: 15.05.2020

Rogers S. 2018 What Nintendo Can Teach Us About Game Design https://www.nyfa.edu/student-resources/nintendocan-teach-us-game-design/ Erişim Tarihi: 23.09.2020

Statista Age of US Video Game Player Since 2010 https:/www.statista.com/statistics/189582/age-of-us-videogame-players-since-2010/ Erişim Tarihi: 20.06.2020

Sega Mega Drive http://www.computinghistory.org.uk/det/2201/Sega-MegaDrive/

Qin H. Rau P. P. ve Salvendy G. 2009 Measuring Player Immersion in the in the Computer Game Narrative, International Journal of Human-Computer Interaction Volume 25, 2009 - Issue 2

Stanton R. 2015 What made Super Mario 64 so special? https:/www.eurogamer.net/articles/2015-04-12-what-madesuper-mario-64-so-special Erişim Tarihi: 19.05.2020

Stuart K. 2015 Sega Saturn: how one decision destroyed PlayStation's greatest rival https://www.theguardian.com/technology/2015/may/14/sega -saturn-how-one-decision-destroyed-playstations-greatestrival Erişim Tarihi: 04.06.2020

Suttner N. 2008 Mirror's Edge Review https://web.archive.org/web/20160528102047/http://www.1 up.com/reviews/mirror-edge Erişim Tarihi: 08.08.2020

Werrner N. 2018 The True Story of the Sega Saturn https://www.svg.com/111172/history-sega-saturn-flop/ Erişim Tarihi: 12.09 .2020

Wiering M., Achten P., Plasmeijer R. 2000. Using Clean for Platform Games, Computing Science Institute, University of Nijmegen 